\title{
Bodily integrity and the sale of human organs
}

\author{
Stephen Wilkinson and Eve Garrard University of Keele, Staffordshire
}

\begin{abstract}
Existing arguments against paid organ donation are examined and found to be unconvincing. It is argued that the real reason why organ sale is generally thought to be wrong is that (a) bodily integrity is highly valued and (b) the removal of healthy organs constitutes a violation of this integrity. Both sale and (free) donation involve a violation of bodily integrity. In the case of the latter, though, the disvalue of the violation is typically outweighed by the presence of other goods: chiefly, the extreme altruism involved in the giving. There is usually no such outweighing feature in the case of the former. Given this, the idea that we value bodily integrity can help to account for the perceived moral difference between sale and free donation.
\end{abstract}

Is there anything wrong with allowing healthy adults to sell one of their kidneys (or any other organ that they can live without) for transplantation? Our aim, in addressing this question, is partly diagnostic and partly justificatory. It is assumed that we in fact think that there's something wrong with organ sale. The aim is to find out what reasons we have for thinking this and to see whether these reasons are convincing. For the purposes of this paper we assume a very sharp distinction between sale and (free) donation. We do recognise, however, that the distinction may, in fact, be rather less sharp than this and that there are important issues which we don't address here, concerning, for example, how to classify compensatory payments.

\section{The case in favour of permitting organ sale}

There's plenty to be said in favour of permitting a trade in human organs. Most obviously, it would generate an increased supply of a scarce and lifesaving resource, as well as providing some much needed income for those who have little else to sell. Furthermore, it seems inconsistent to allow bomb-

\section{Key words}

Ethics; organ donation; organ sale; bodily integrity; transplantation. disposal experts, fire-fighters and deep-sea divers to be paid for their dangerous (and sometimes painful) work, while preventing other people from being paid for the equally valuable contribution their kidneys would make to the well-being of others. Finally, libertarian thoughts might incline us to permit people to dispose of their own body parts in whatever way they wish (we're talking about their body parts, after all, and so they should be allowed to do what they want with them). ${ }^{1}$

In spite of these considerations, though, many still find the idea of paying a healthy person for one of her organs deeply repugnant. Given the apparend advantages of permitting organ sale, what justificae tion might there be for this reaction?

\section{The case against permitting organ sale}

There seem to us to be four standard objections to permitting organ sale, each of which we regard as ultimately unconvincing.

\section{PAIN AND RISK}

The first is simply that the organ seller is subjected to an extremely high level of pain and risk. This in itself, though, can't be sufficient to justify a ban on organ sale, since we don't in general think that it's wrong to pay people for doing dangerous things. (There are numerous examples of this: fire-fighters, astronauts, miners and divers, to name but a few.) Common forms of "risky labour" are often more dangerous than organ sale, but are regarded as heroic, rather than condemned; it is seen as quite proper to reward those who do them. And this difference in attitude can't be justified in terms of the good consequences that "risky labour" produces, since the consequences of an organ sale (typically, saving a life) may be just as good or better.

\section{EXPLOITATION AND COMMODIFICATION}

The second worry is that the relationship between the buyer and seller is likely to be exploitative and to either cause or constitute an unacceptable commodification of the seller and/or her body. Brecher, for example, describes trading in human kidneys (along with many other practices) as 
"exploitation based on making a commodity of human beings". ${ }^{2}$

There are two problems with this objection. First, although organ sale does necessarily involve treating a human body part as a commodity, there is no reason to suppose that this is necessarily exploitative. Would we really regard it as exploitative if the organ seller were wealthy, educated, rational and wellinformed and got paid $£ 1,000,000$ for her organ? Second, we do, in fact, permit many practices which are at least as exploitative and "commodifying" as organ sale (for example poorly paid labour). Of course, this doesn't show that exploitation and commodification are acceptable. But it does show that they aren't a special problem for organ sale and that they alone can't explain why organ sale is seen as more offensive than (say) low wages. (It may, of course, be argued that the thought that organ sale is worse than low wages is simply irrational and/or false. This is, roughly, Bob Brecher's view. $)^{3}$

It is sometimes claimed, however, that there is an important difference between banning a proposed new practice and banning an established one, since banning an established one will be more disruptive, unpopular and costly. This might provide a reason for banning organ sale, even if it were morally no worse than other permitted exploitative practices. For we could hold that although, as an ideal, we should ban all exploitative practices, in the real world we must settle for banning just those which we can ban, or can ban without excessive disruption and cost. However, although the distinction between banning new and banning existing practices is an important one, it is not sufficient to show that organ sale is morally worse than these other exploitative practices and so won't serve to explain or justify the widespread moral intuition that there is something especially objectionable about the sale of body parts. In short, it seems that the moral difference between organ sale and poorly paid labour is not merely that one is easier to ban than the other.

\section{UNDERMINING THE PRACTICE OF FREE DONATION}

Another objection to permitting organ sale is that to do so would undermine the practice of free donation. Abouna et al, for example, claim that there is "considerable evidence to indicate that marketing in human organs will eventually deprecate and destroy the present willingness of members of the public to donate their organs out of altruism". ${ }^{4}$ There are two distinct worries here. The first is a purely practical one. If payment is allowed, then virtually all donors will begin to expect payment and so voluntary donations will cease. The second is that allowing payment for organs would deprive people of an opportunity to participate in "giving" relationships with one another: relationships which have some ethical or social value, independently of their practical consequences.
Taking the second worry first, it is sufficient to point out that the mere permissibility of sale doesn't itself prevent people from donating (although it might, of course, encourage them to sell rather than donate). Organ givers are at liberty to waive their fee and, in a sense, the possibility of sale allows the (free) donor to be even more generous than she could otherwise have been; for not only does she give up her organ, but she gives up her fee as well.

As regards the first worry, it seems that there's no compelling reason to believe that organ sale would undermine the practice of free donation. After all, professional social work and charitable social work co-exist. Also, if organ sale led to a significant overall increase in the supply of organs, this would more than compensate for the reduced number of free organs. But in any case, it is far from clear that there is a significant practice of free donation to be undermined. As Harvey points out, "it is doubtful that there is a great number of willing, non-related potential organ-donors who will give without payment". ${ }^{5}$ Given the high level of pain and risk involved, free donation (except by relatives, who might well waive the fee, if it were offered) is very unlikely to take place anyway.

CONCERNS ABOUT AUTONOMY AND CONSENT

It is generally agreed that the absence of coercion and manipulation is required for genuine consent. And the final objection we consider is that no one? could ever be in a position autonomously to consent to selling an organ such as a kidney, since the process would be so unpleasant and/or dangerous that only someone who was coerced or manipulated would agree to it. One virtue of this objection is that it would explain why we're more concerned about organ selling, than the selling of blood and certain other body products. In the case of the latter, the level of pain and/or risk is very low, and so the need for coercion and manipulation is much less.

This objection does, indeed, raise a serious practical worry about the possibility of organ sellers being coerced, and it is certainly true that, were organ sale to be permitted, rigorous safeguards aimed at ensuring fully informed consent in every case would be required. But does organ sale necessarily involve coercion or manipulation? It seems not, since even a wealthy, informed and rational agent might consent to it (without coercion or manipulation) if the price were high enough. Would we want to say, in such a case, that the person hadn't really consented? (Of course, with a broad enough conception of manipulation, the answer to this question might be "yes", but we would question whether so broad a conception would be able to do any ethical work, since too many things would be counted as manipulative.)

Also, given that organ sale is less unpleasant and dangerous than many accepted forms of "risky labour", were we to take this objection seriously, 
then a wide range of accepted practices should be condemned on similar grounds. What is more, the same line of reasoning might lead us to ban many cases of organ donation, for as Harvey points out:

". . . there is financial pressure when the potential [paid] donor is in poverty. And perhaps it may be argued that this alone is sufficient for banning all paid-for donations. But then, in consistency, the same reasoning should be applied to related donors: since some of them, are open to heavy psychological and emotional pressure (for example, perhaps by being the submissive and 'guilt'-ridden offspring of an extremely domineering and now ailing parent)" $\ldots 6^{6}$

If the possibility of (financially) pressuring the organ seller is sufficient to warrant a ban on organ sale, then the possibility of (emotionally) pressuring the related organ donor must also be sufficient to warrant a ban on organ donation. But since we clearly don't want to ban donation, the possibility of pressuring can't be a sufficient reason to ban sale.

In response to this, it might be argued that financial and emotional pressures are importantly different, in that financial pressure is more erosive of the possibility of genuine consent. This may well be true. The pressure on someone facing starvation (due to poverty) may well be such that an offer to buy her kidney is irresistible. However, a not unreasonable reply is that in those circumstances, if the potential seller's plight cannot (or will not) be relieved in any other way, then forbidding her to sell her kidney is more harmful to her than undermining her autonomous consent (by allowing her to sell it). Furthermore, the evil involved here seems to lie not in the sale itself, but in her being allowed to be in such desperate circumstances in the first instance.

\section{Brecher's view: organ sale and commercial values}

Brecher argues that if we confine ourselves to the standard principles of biomedical ethics (beneficence, non-maleficence etc) then we won't find anything wrong with organ sale. This is because arguments counting against organ sale will count equally against other accepted practices (for example "risky labour"). ${ }^{3}$

He thinks that what's wrong with organ sale is that it institutionalises and encourages a particular set of values: namely, "the commercial values of the free market". If we accept these values and the sort of society with which they are associated, we should accept organ sale. But in fact we ought to accept neither organ sale nor the "commercial values" that underpin it. Organ sale, for him, is just an extreme case of the unacceptably commercial values that have already permeated other aspects of our society.
"The purchase of kidneys for transplant differs from the purchase of blood, renting of a body, or purchase of another's health . . . only in its symbolising the nature of all these transactions. Perhaps that is why it raises such a furore - just as Shylock might do in bringing home to an audience truths about the society they live in."2

But the main problem with the Brecher analysis is precisely that it makes the rejection of organ sale dependent on the global rejection of commercial values. This seems not to fit well with two facts First, both opponents and proponents of commercial values (often) oppose organ sale; and second, there is a widely held view that the commercialisation of human body parts is somehow worse than commercialisation of other objects or services. Both of these facts suggest that many opponents of organ sale (rightly or wrongly) believe that its wrongness does not lie just in its commercialism. For when both proponents and opponents of a general view share a particular moral intuition, then it's plausible to suppose that that intuition is not the product of the general view.

Of course, the mere existence of these moral intuitions doesn't count decisively against the Brecher view, for we may just be dealing with irrational and inconsistent attitudes here. But it would be better we could find an argument for the wrongness o organ sale which could both preserve these intuitions and be persuasive even for those who, in general, accept commercial values.

\section{The structure of the problem: organ sale and "risky labour"}

The structure of the problem is this. Arguments that would show that organ sale is morally dubious seem also to show either that payment for risky labour is morally dubious or that organ donation is morally dubious. We need to identify some morally relevant feature which distinguishes organ sale from both these other activities. We start by considering some differences between organ sale and risky labour.

\section{VIOLATION OF BODILY INTEGRITY: CERTAINTY AND} RISK

For organ sale, violation of bodily integrity is a certainty. Indeed, it is an essential part of giving up an organ. For risky labour, on the other hand, although there is always a danger of bodily damage, it is only a danger. It is at least possible to spend one's whole life engaged in a dangerous occupation without actual bodily damage ever occurring. One might also invoke the doctrine of double effect here. For risky labour (or at least for many cases of it) violation of bodily integrity is intended neither as an end nor a means; it is a mere foreseen (perhaps merely foreseeable) consequence. This, though, is not true of organ sale. Violation of bodily integrity is 
an intended end, or at least an intended means to some other end (saving another's life).

\section{AUTONOMOUS ACTION AND PASSIVITY}

Risky labour contains at least the possibility, and often the reality, of autonomous action (for example in the exercise of occupational skills). But organ sale (after the initial decision) is entirely passive and unskilled. (No one could be good at having an organ removed.) Such passivity invites the withdrawal of the "intentional stance". ${ }^{7}$ The seller is (temporarily) seen as an entirely passive object - like an "organ farm".

\section{SELLING PARTS AND SELLING PRODUCTS}

Risky labour typically involves the selling of a product or service arising out of labour. The organ seller, though, provides only a body part. What she is selling is (in a sense) a part of herself, rather than the product of her conscious actions. ${ }^{8}$

\section{IRREPLACEABILITY AND UNIQUENESS}

The organ seller loses something unique and irreplaceable. Although risky labour does carry some danger of this, it is not certain or necessary. One reason for thinking that replaceability and uniqueness considerations are important, is that they explain two other moral intuitions. First, we generally think that selling body parts (such as kidneys) is a much more serious matter than selling body products (such as blood and hair). Second, we generally think that selling some types of body product (such as sperm and $o v a$ ) is a much more serious matter than selling other types (again, blood and hair).

Our differing reactions here can be accounted for by appealing to thoughts about replaceability and uniqueness. Blood and hair are very obviously replaceable, while kidneys are very obviously not. (And it seems plausible to think that if humans grew new kidneys, after having lost one, then our concern about having them removed would be much less.) Sperm and ova, though, represent an intermediate case.

The thought is that body products such as blood and hair are both replaceable and not unique in $a$ relevant way. Although, strictly speaking, no two hairs or blood cells are exactly alike, these are differences which make no difference. We don't really care whether or not our new hairs are qualitatively identical with our old ones, provided that the new and old ones share roughly the same surface properties. We might be concerned if our hair turned grey overnight, since this is an observable difference with some significant consequences, but the exact biochemical make-up of our hair is not something which is of any concern to us. Hair, then, is very obviously and very easily replaceable: exact qualitative similarity is not required for a new head of hair to count as a perfect replacement.

This, however, is clearly not true of organs (which are, in fact, irreplaceable) and may not be true of sperm and ova. Although there is a sense in which the latter are replaceable, we do take the (genetic) differences between individual sperm and ova seriously, because these are differences that can make a difference (for example to the genetic make-up of possible persons). No two hairs are the same and no two sperm are the same. But the differences in the case of the latter are differences that we care about, and with good reason. What this amounts to is the idea that, for sperm and ova, the conditions for what counts as a perfect replacement are much tougher to meet. Sameness of surface features (appearance etc.) clearly won't be enough. What we need is at least exact qualitative similarity. And perhaps (given worries about the identity of resultant persons) even that won't be enough, in which case particular sperm and ova will turn out to be, strictly speaking, irreplaceable.

\section{Sale and donation: what's the difference?}

Perhaps, then, our different attitudes towards organ sale and risky labour can be explained and/or justified by appealing to one or more of the above differences. This, though, still leaves us with a problem. If organ sale were wrong just in virtue of its having some or all of the above features, then surel organ donation would be wrong too, since these are all features that it shares with organ sale. Clearly organ donation is not wrong, so we must choose one of the following options.

(a) Organ sale is not wrong either.

(b) Organ sale is wrong, but not in virtue of its having any of the above features.

(c) Organ sale is wrong in virtue of a combination of its possessing the above features plus its possessing or lacking some other relevant feature (some further feature which accounts for there being a morally significant difference between sale and donation).

On the face of it the only difference between sale and donation is payment in the case of the former. But this alone can't be the feature which accounts for the unacceptability of organ sale, because the very thing that we're trying to explain is why payment is morally relevant here.

In some contexts, of course, non-payment (doing things for free) is seen as the mark of something admirable (for example volunteer mountain-rescue teams, charity workers and life-boat crews). Here, what seems to be at issue is purity of motive. The volunteer rescuer acts from pure altruism (let's assume) whereas the professional will, at best, have mixed motives: altruism plus financial reward. Perhaps some such thought is at work in the case of organ donation. The organ donor (at least in the favourable cases) is motivated by pure altruism, whereas the organ seller, like the professional risktaker, is likely to have mixed motives. 
But it is still unclear why the lessened purity of motive involved in organ sale is sufficient to warrant a prohibition. In the analogous cases considered (for example charity work), the unpaid action is seen as supererogatory (more than is morally required). In such cases, payment is permissible (we have professional social workers etc). The absence of payment makes it supererogatory; so the presence of payment merely renders it non-supererogatory. Organ donation is (often) supererogatory; so payment would seem merely to make it non-supererogatory, rather than impermissible.

\section{A moral hypothesis: bodily integrity and pure altruism}

One way of explaining the moral significance of organ removal is by appealing to the notion of bodily integrity. The idea is that bodily integrity has (or is at least regarded as having) intrinsic value. This may not be the sort of intrinsic value that we want to maximise (we don't necessarily think that it's good to maximise the number of bodies with integrity). But it is at least the sort of value which makes it wrong or bad (other things being equal) to deprive bodies of their existing integrity. (Dworkin usefully distinguishes between instrumental and intrinsic value and then, within intrinsic value, between incremental and inviolable (or sacred) value. The latter is that form of value which doesn't, or shouldn't, carry with it a desire to maximise.) ${ }^{9}$

Bodily integrity is seriously violated by the loss of irreplaceable body parts. The extent of the violation depends (amongst other things) on the extent to which the parts in question are irreplaceable or unique, and the extent to which the parts in question play a central role in the functioning of the whole body (hence, we care more about kidneys and lungs, than about toes and appendices). The wholeness of the body is best construed functionally, rather than spatio-temporally, such that being an "integral part" is not merely a matter of being attached and/or internal to the body, but a matter of contributing to the body as a functional whole (hence, the removal of malfunctioning organs or tumours or functionally insignificant body parts poses little or no threat to bodily integrity).

Given the felt value of bodily integrity, actions which involve the violation of bodily integrity will be wrong, all other things being equal. However, other things aren't always equal, and our valuing of bodily integrity can be overridden by other considerations (but only by quite serious ones). In typical cases of organ donation, the wrongness of violating bodily integrity is overridden by a combination of extremely good consequences (for example the saving of an other's life) and the pure altruism involved in the giving. The act of donating (strictly speaking, of deciding to donate) is highly valued because of its altruism. We may just straightforwardly identify altruism as a good.
Or we could give more complex (and loosely Kantian) reasons for valuing this sort of altruistic act. (Roughly, such acts are free and autonomous and rational in virtue of their not being grounded in desire.)

We now have some sort of answer to our original question: why is organ sale seen as a bad thing? In short, the answer is that it is bad because it involves the violation of bodily integrity. On its own, of course, this doesn't morally distinguish sale from donation. (Both involve violation of bodily integrity.) But in the case of organ donation the disvalue of the body's being violated is typically "defeated" or outweighed by the value placed on the purity of the motive and the positive outcome.

Our view doesn't imply that organ donation is always permissible or that organ sale is always wrong. The motives, even in the case of organ donation, may be the wrong ones. Conversely, there may be some cases of organ sale which are extraordinarily purely motivated. For example, there is the "double altruism case" where someone both sells her organ and donates the money to pay for someone else's operation. ${ }^{10}$ These cases are as permissible and as good as organ donation and for the same reasons.

\section{CIRCULARITY AND TRIVIALITY}

It may be objected that our appeal to bodily integrity doesn't really explain anything. All that the preserva-e tion of bodily integrity amounts to is the nonremoval of integral body parts. Therefore, we can't explain the prima facie wrongness of removing body parts by appealing to the value of bodily integrity. For to say that we value bodily integrity is just to say that we value the non-removal of body parts. In short, our view amounts to the trivial claim that we oughtn't to remove body parts because we value their non-removal. (To a great extent, we owe this objection to Richard Norman, who raised it during a discussion of an earlier version of the paper, given at the University of Kent in June 1995.)

What we need to show, then, is that the concept of bodily integrity amounts to something more or other than the mere non-removal of body parts. Clearly, to attempt to offer a complete general account of bodily integrity is outside the scope of this paper. We can, however, offer some reasons for thinking, firstly, that the concept of bodily integrity is a more general concept than the non-removal of body parts (ie there are ways of violating bodily integrity that don't involve body part removal) and, secondly, that the idea of bodily integrity does important "ethical work" in situations which have nothing to do with organ removal.

Consider cases of rape, assault and non-consensual investigative surgery. These all seem to be prima facie wrong. One major reason for regarding all of these as wrong is that they inflict pain (both physical and "psychological") on their victims. But neither pain nor bodily damage are essential features. In each case, at least in principle, the victim could have been 
unconscious throughout and never become aware of what has happened to her. Would the victim have been harmed if there were no pain or bodily damage of any sort? Intuitively, the answer seems to be "yes". And the best explanation of this would seem to be that her bodily integrity has been violated.

This goes some way towards showing that the body's integrity can be violated without the body being damaged in any way (in particular, without any part of it being removed) and that the concept of body part removal is distinct from (though related to) the concept of violation of bodily integrity. But if bodily damage and removal of parts are not essential features of integrity-violation, what exactly does integrity-violation amount to? The analysis we propose is that a body's integrity is violated if either: (i) it is "spatially invaded"; or (ii) its normal functioning is interfered with; or (iii) both (i) and (ii). That (i) alone is sufficient can be seen by looking at the rape case in which the victim is unconscious and (physically) undamaged. That (ii) alone is sufficient can be seen by considering such things as poisoning. Admittedly, even in the case of poisoning, there is some "invasion" involved (the poison enters the body) but the harm here is not in the entering, but in the malfunction caused; and if there were a case in which malfunction were caused without any substance entering the body, then it would still be classed as a violation. In the case of organ removal both (i) and (ii) are satisfied. The body is spatially invaded and its normal functioning is interfered with.

It is also worth noting that our legal concept of battery seems grounded in an idea of the body's integrity being violated, which is not unlike the one just sketched. In particular, neither bodily damage, nor body part removal, nor pain are essential. Mere spatial invasion, or non-consensual touching, is sufficient.

\section{Conclusion}

The bodily integrity hypothesis is an attempt to provide a rational reconstruction of why we do in fact think that there's something wrong with organ sale. It may also provide a justification of our view, provided that its assumptions are correct. If we rightly value bodily integrity and rightly take thoughts about replaceability and uniqueness seriously, then our aversion to selling organs is indeed justified (at least for the more "standard" cases).

The alternative is an error theory; we do in fact value bodily integrity, but are wrong to do so. Any plausible error theory of our valuing this feature should provide some account of why we (erroneously) endorse this value. Such an account might take a biopsychological form. For example, evidence from studies of very young infants suggests that the ability to recognise and respond to human body outlines is innate, rather than learned. ${ }^{11}$ It is a fairly plausible assumption that such innate capacities have, or at least have had, some survival value (since their presence in us suggests past selection pressure in their favour). An inclination to value that which we are innately and beneficially pre-disposed to show preferential interest in, seems a natural further development. (Here, of course, the innate body schema is characterised in spatial terms. But a spatially defined body schema could provide the basis for the acquisition of a more functional conception of bodily integrity.)

If, however, we think that the value we apparently place on the maintenance of bodily integrity can be justified, then an obvious place to seek such a justification would be in bodily theories of personhood and personal identity. (Chadwick seems to appeal to a view of this kind. $)^{8}$ Such complex metaphysical issues cannot be addressed within the confines of this paper, but further research into the relation between the metaphysics of personal identity and problems in applied ethics, such as the moral permissibility of organ sale, would be of considerable interest and importance. ${ }^{12}$

Stephen Wilkinson, BA, MA, DPhil, and Eve Garrard, $B A, M P h i l$, are both Lecturers in Philosophy at the University of Keele.

\section{References and notes}

1 Various arguments in favour of permitting organ sale including some of the ones that we've noted, can be found in: Reddy K. Organ donation for consideration: an Indian point of view. In: Land W, Dossetor J, eds. Organ replacement therapy: ethics, justice, commerce. Berlin: Springer-Verlag, 1991: 173-80.

2 Brecher B. The kidney trade: or, the customer is always wrong. Fournal of Medical Ethics 1990; 16: 122.

3 Brecher B. Organs for transplant: donation or payment? In: Gillon R, ed. Principles of health care ethics. Chichester: John Wiley and Sons, 1994: 993-1002.

4 Abouna G, et al. The negative impact of paid organ donation. See reference 2: 167 .

5 Harvey J. Paying organ donors. Fournal of Medical Ethics 1990; 16: 119.

6 See reference 5: 118 .

7 Dennett D. Brainstorms: philosophical essays on mind and psychology. Montgomery, Vermont: Bradford, 1978: 237-8.

8 For a helpful discussion of this (and related) issues see: Chadwick $R$. The market for bodily parts: Kant and duties to oneself. In: Almond B, Hill D, eds. Applied philosophy: morals and metaphysics in contemporary debate. London: Routledge, 1991: 288-99.

9 Dworkin R. Life's dominion. London: Harper Collins, 1993.

10 See reference 3: 996.

11 Melhaer J, Dupoux E. What infants know. Oxford: Blackwell, 1994.

12 An interesting recent defence of the bodily view of personhood and personal identity can be found in: Olson E. Is psychology relevant to personal identity? Australasian Fournal of Philosophy, 1994; 72: 173-86. 